\title{
Selection of and Retention in Surgical Specialty during Early Career in Japan
}

\author{
Yasuko Tomizawa, ${ }^{1}$ Satoru Miyazaki, ${ }^{2}$ Takako Matsumoto ${ }^{3}$ and Yoshio Uetsuka ${ }^{4}$ \\ ${ }^{1}$ Department of Cardiovascular Surgery, Tokyo Women's Medical University, Tokyo, Japan \\ ${ }^{2}$ Department for Education Policy and Evaluation Research, National Institute for Educational Policy Research, \\ Tokyo, Japan \\ ${ }^{3}$ Department of Thoracic Surgery, Tokyo Women's Medical University, Tokyo, Japan \\ ${ }^{4}$ Institute of Geriatrics, Tokyo Women's Medical University, Tokyo, Japan
}

The number of surgeons is decreasing in Japan. We investigated the trend and factors influencing surgeons' selection of and retention in surgical specialty. In 2016, we obtained data of biennial surveys conducted by the government, and analyzed the annual data of doctors up to the latest available survey at that time (survey, 1994-2014; medical license acquisition, 1993-2014). The rate of selecting surgery by male and female doctors during early career (first three surveys after acquiring medical license) decreased from $28.1 \%$ in 1994 to $21.3 \%$ in 2010 (first to nineth survey). Female surgeons increased from $7.8 \%$ in 1993 to $12.4 \%$ in 2003 , but decreased from $12.5 \%$ in 2006 to $10.7 \%$ in 2010 . Total number of surgeons declined throughout the period. In females, the rate of selecting surgery tended to increase at the beginning of the new training system in 2004, but declined slightly thereafter. The retention rate in those who selected surgery at least once by the third survey (1998) after acquiring medical license in 1993 showed a downward trend. The retention rate in females declined continuously to $48.4 \%$ in 2002 , stabilized thereafter, and then increased from $47.6 \%$ in 2006 to $50.8 \%$ in 2014 . The retention rate after 10 years (1993-2003) was almost stable $(72.4 \%)$ in males, but increased to $57.5 \%$ in females, and the gender difference tended to decrease. Younger doctors tend to value their private life, and may not choose or continue to practice surgery unless working conditions in surgery improve and income is commensurate with their work.

Keywords: generation gap; retention rate; selection rate; surgery; work-life balance

Tohoku J. Exp. Med., 2020 October, 252 (2), 95-102.

\section{Introduction}

The total number of surgeons had been decreasing, and the number of young surgeons also decreased in Japan (Tomizawa 2013). Recent statistics have shown a decrease of more than 1,000 surgeons compared to twenty years ago (Ministry of Health Labor and Welfare 2004).

The clinical training in Japan was revised in 2004. In the new clinical training system, physicians engaged in medical practice must undergo mandatory clinical training for more than two years at a university-affiliated hospital or a hospital designated by the Ministry of Health, Labor and Welfare (2004). After ten years, as "bright side and dark side" of the new clinical training system, the benefits were improvement of basic clinical competence of residents and improvement of their working conditions including guaranteed status and financially compensation (Iinuma et al. 2010), while disadvantages included shortage of local doctors (Kitamura 2015).

Young doctors who just acquire the doctor's license may want to choose surgery, but their enthusiasm may be dampened when they see the reality of a surgeon's life during rotation in the new clinical training system. Residents expect to see surgeons as respectable positive role model in the operating room, who spend sufficient time with family and maintaining good work-life balance (Yamazaki et al. 2010). They saw that surgeons are exhausted from working long hours and doing chores until late at night as overtime. They often take up additional part-time job in outpatient clinics of related hospitals due to the low salary from uni-

Received March 30, 2020; revised and accepted August 24, 2020. Published online September 15, 2020; doi: 10.1620/tjem.252.95.

Correspondence: Yasuko Tomizawa, Department of Cardiovascular Surgery, Tokyo Women's Medical University, 8-1 Kawada, Shinjuku-ku, Tokyo 162-8666, Japan.

e-mail: tomizawa.yasuko@twmu.ac.jp

Presented at Forum Session at Clinical Congress 2018, American College of Surgeons, Boston, MA, USA

(C)2020 Tohoku University Medical Press. This is an open-access article distributed under the terms of the Creative Commons Attribution-NonCommercial-NoDerivatives 4.0 International License (CC-BY-NC-ND 4.0). Anyone may download, reuse, copy, reprint, or distribute the article without modifications or adaptations for non-profit purposes if they cite the original authors and source properly.

https://creativecommons.org/licenses/by-nc-nd/4.0/ 
versity hospital, and as a contribution to community medicine. Residents may decide not to choose surgery when they recognize the tired surgeon as themselves in the mirror of the future. As a result, it may be true that the new training system may impact young doctors in their choice of surgical specialty and in retaining in the specialty. In this study, we investigated the recent trend of choice of surgery by analyzing gender and the year of acquisition of doctor's license.

\section{Methods}

The Japanese government has been conducting biennial surveys on doctors, dentists and pharmacists on December 31 of the year of survey. In the spring of 2016, we sent an application to the Ministry of Health, Labour and Welfare for permission (Statistics Law Article 33) to obtain the data of doctors up to the latest available survey at that time (1994 to 2014). This study was an analysis of data only, and approval from institutional ethics committee was not required.

In this study, "Surgery" includes general surgery, respiratory surgery, cardiovascular surgery, trachea and esophageal surgery, pediatric surgery, digestive surgery (gastroenterological surgery), orthopedics, plastic surgery, cosmetic surgery, breast surgery, brain neurosurgery and anal surgery.

Serial data of individual doctors collected over multiple years was integrated based on the doctors' license numbers. The data of doctors who were 24 to 28 years of age on December 31 of the year when they acquired the doctors' license were included in this study. Doctors who were engaged in multiple specialties, while the main specialty was surgery were included in this study. The total number of doctors responded (total number of respondents) in 19942014, was 2,983,036. Doctors who failed to return the survey more than twice during the study period were excluded due to data deficiency. Eventually, the total number of subjects analyzed in this study was 110,359 (males: 75,599, females: 34,760).

Regarding changes in the survey form for doctors, "resident" was not included as a choice of the clinical department in which the doctor was working in December 2004, while "resident" was included as a choice in December 2006, and "clinical resident" was included as a choice in December 2008.

The situations at the initial survey after doctors' license acquisition are shown in Table 1. In this table, the total number of subjects analyzed for each license year group is shown as "Number analyzed." The situations when "surgery" was selected as the specialty for the first time are shown in Table 2. A doctor who selected surgery at least once by the third survey after doctor's license acquisition was defined as one who chose surgery as early career. In this study, selection of and retention in surgical specialty during early career were examined.

\section{Results}

\section{Early surgical career in the survey}

Cumulatively over 90\% (except in 2005-2006 and 2009-2010) of the doctors working in the surgical field chose surgery as the major specialty at the second survey and over $95 \%$ at the third survey (Table 2). These data indicate that most of the doctors who work in a surgical department by the third survey chose "surgery" as specialty in their early career.

\section{Selecting surgery as specialty in early career}

The proportion of newly licensed female doctors exceeded 30\% since 1999 (Fig. 1). The number of male doctors and total number of doctors (male and female combined) who chose surgery in early career showed a decreasing trend throughout the study period.

The proportion of all doctors (males and females combined) who selected surgery decreased from $28.1 \%$ in 1993 to $21.3 \%$ in 2010 (Fig. 2). The proportion of male doctors choosing surgery was higher than that of female doctors throughout the study period. The proportion of female doctors selecting surgery increased from $7.8 \%$ in 1993 to $12.4 \%$ in 2003 , followed by a sharp rise in 2004 and an equally sharp decline; thereafter the percentage decreased

Table 1. The situation at the initial survey after medical license acquisition.

\begin{tabular}{|c|c|c|c|c|c|c|c|c|c|c|}
\hline \multirow{2}{*}{$\begin{array}{l}\text { Year of medical } \\
\text { license acquisition } \\
\text { Year of initial survey }\end{array}$} & & \multicolumn{9}{|c|}{ 1993-1994 1995-1996 1997-1998 1999-2000 2001-2002 2003-2004 2005-2006 2007-2008 2009-2010 } \\
\hline & & 1994 & 1996 & 1998 & 2000 & 2002 & 2004 & 2006 & 2008 & 2010 \\
\hline Number analyzed & & 12,500 & 12,489 & 12,503 & 11,550 & 12,668 & 12,169 & 12,107 & 12,177 & 12,196 \\
\hline \multirow{4}{*}{ Clinical specialty } & Surgery & $24.2 \%$ & $23.4 \%$ & $23.1 \%$ & $22.6 \%$ & $21.3 \%$ & $14.4 \%$ & $0.5 \%$ & $0.3 \%$ & $0.2 \%$ \\
\hline & Other specialties & $74.3 \%$ & $74.8 \%$ & $75.1 \%$ & $76.3 \%$ & $76.8 \%$ & $84.4 \%$ & $3.1 \%$ & $1.7 \%$ & $1.2 \%$ \\
\hline & Residents & - & - & - & - & - & - & $96.0 \%$ & $97.4 \%$ & $97.8 \%$ \\
\hline & Specialty unknown & $0.2 \%$ & $0.2 \%$ & $0.6 \%$ & $0.2 \%$ & $0.9 \%$ & $0.7 \%$ & $0.2 \%$ & $0.3 \%$ & $0.6 \%$ \\
\hline Non-clinical specialty & & $1.2 \%$ & $1.3 \%$ & $1.0 \%$ & $0.8 \%$ & $0.8 \%$ & $0.5 \%$ & $0.2 \%$ & $0.2 \%$ & $0.1 \%$ \\
\hline Unemployed, others & & $0.1 \%$ & $0.2 \%$ & $0.2 \%$ & $0.1 \%$ & $0.2 \%$ & $0.1 \%$ & $0.1 \%$ & $0.0 \%$ & $0.1 \%$ \\
\hline
\end{tabular}


Table 2. The year when "surgery" was first selected as the major specialty.

\begin{tabular}{|c|c|c|c|c|c|c|c|c|c|c|c|c|}
\hline \multirow{2}{*}{$\begin{array}{l}\text { Year of license acquisition } \\
\quad \text { (number surveyed) }\end{array}$} & & \multicolumn{11}{|c|}{ Number of survey after license acquisition } \\
\hline & & 1 & 2 & 3 & 4 & 5 & 6 & 7 & 8 & 9 & 10 & 11 \\
\hline 1993-1994 & New & $82.8 \%$ & $10.8 \%$ & $2.3 \%$ & $1.3 \%$ & $0.8 \%$ & $0.5 \%$ & $0.4 \%$ & $0.5 \%$ & $0.2 \%$ & $0.2 \%$ & $0.2 \%$ \\
\hline$(\mathrm{n}=3,654)$ & Cumulative & $82.8 \%$ & $93.6 \%$ & $95.9 \%$ & $97.2 \%$ & $98.0 \%$ & $98.5 \%$ & $98.9 \%$ & $99.5 \%$ & $99.6 \%$ & $99.8 \%$ & $100.0 \%$ \\
\hline $1995-1996$ & New & $82.2 \%$ & $10.2 \%$ & $3.1 \%$ & $1.6 \%$ & $0.8 \%$ & $0.6 \%$ & $0.5 \%$ & $0.3 \%$ & $0.5 \%$ & $0.2 \%$ & \\
\hline$(\mathrm{n}=3,559)$ & Cumulative & $82.8 \%$ & $92.4 \%$ & $95.5 \%$ & $97.1 \%$ & $97.9 \%$ & $98.5 \%$ & $99.0 \%$ & $99.3 \%$ & $99.8 \%$ & $100.0 \%$ & \\
\hline $1997-1998$ & New & $80.9 \%$ & $12.2 \%$ & $2.9 \%$ & $1.2 \%$ & $1.0 \%$ & $0.7 \%$ & $0.4 \%$ & $0.4 \%$ & $0.3 \%$ & & \\
\hline$(\mathrm{n}=3,570)$ & Cumulative & $80.9 \%$ & $93.1 \%$ & $96.0 \%$ & $97.3 \%$ & $98.2 \%$ & $98.9 \%$ & $99.3 \%$ & $99.7 \%$ & $100.0 \%$ & & \\
\hline $1999-2000$ & New & $81.0 \%$ & $12.4 \%$ & $3.0 \%$ & $1.1 \%$ & $1.0 \%$ & $0.5 \%$ & $0.5 \%$ & $0.4 \%$ & & & \\
\hline$(\mathrm{n}=3,218)$ & Cumulative & $81.0 \%$ & $93.4 \%$ & $96.4 \%$ & $97.5 \%$ & $98.5 \%$ & $99.1 \%$ & $99.6 \%$ & $100.0 \%$ & & & \\
\hline 2001-2002 & New & $79.4 \%$ & $14.7 \%$ & $2.8 \%$ & $1.4 \%$ & $0.7 \%$ & $0.6 \%$ & $0.5 \%$ & & & & \\
\hline$(\mathrm{n}=3,405)$ & Cumulative & $79.4 \%$ & $94.0 \%$ & $96.9 \%$ & $98.2 \%$ & $98.9 \%$ & $99.5 \%$ & $100.0 \%$ & & & & \\
\hline 2003-2004 & New & $51.2 \%$ & $39.8 \%$ & $6.1 \%$ & $1.9 \%$ & $0.7 \%$ & $0.4 \%$ & & & & & \\
\hline$(\mathrm{n}=3,415)$ & Cumulative & $51.2 \%$ & $90.9 \%$ & $97.1 \%$ & $98.9 \%$ & $99.6 \%$ & $100.0 \%$ & & & & & \\
\hline $2005-2006$ & New & $2.1 \%$ & $85.6 \%$ & $8.8 \%$ & $2.4 \%$ & $1.2 \%$ & & & & & & \\
\hline$(\mathrm{n}=2,868)$ & Cumulative & $2.1 \%$ & $87.7 \%$ & $96.4 \%$ & $98.8 \%$ & $100.0 \%$ & & & & & & \\
\hline 2007-2008 & New & $1.5 \%$ & $88.6 \%$ & $6.9 \%$ & $3.1 \%$ & & & & & & & \\
\hline$(\mathrm{n}=2,795)$ & Cumulative & $1.5 \%$ & $90.1 \%$ & $96.9 \%$ & $100.0 \%$ & & & & & & & \\
\hline 2009-2010 & New & $1.1 \%$ & $76.6 \%$ & $22.3 \%$ & & & & & & & & \\
\hline$(\mathrm{n}=2,655)$ & Cumulative & $1.1 \%$ & $77.7 \%$ & $100.0 \%$ & & & & & & & & \\
\hline
\end{tabular}

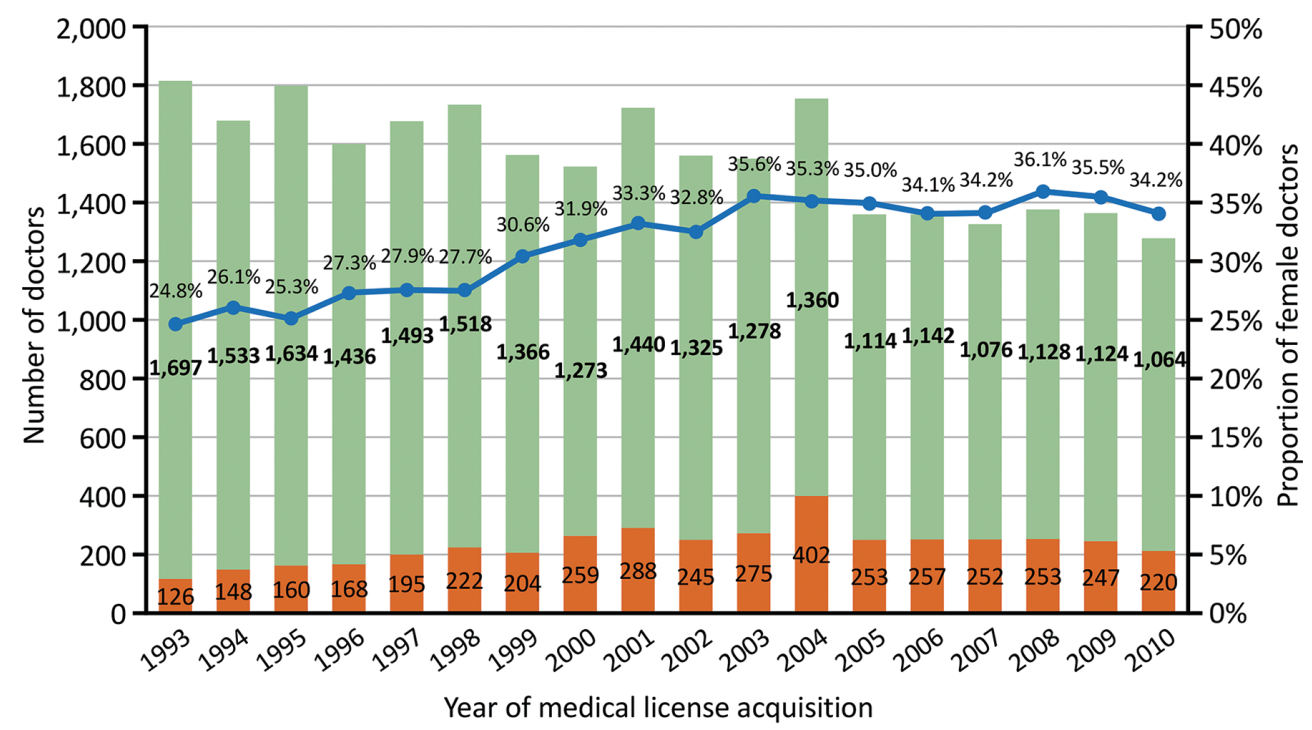

\section{Number of males selecting surgery $\quad$ Number of females selecting surgery Proportion of newly licensed female doctors (reference)}

Fig. 1. Numbers of male and female doctors selecting "surgery" in early career and proportion of female doctors acquiring new medical license.

The total number of surgeons declined throughout the period. Proportion of female doctors new medical license acquisition is larger than $30 \%$ since 1999 . Green bar shows the number of males selecting surgery, orange bar indicates the number of females selecting surgery, and the blue line shows the proportion of newly licensed female doctors as reference.

gradually from $12.5 \%$ in 2006 to $10.7 \%$ in 2010 . The total number of surgeons declined throughout the study period. In females, the proportion tended to increase before the new training system in 2004, but flattened or declined slightly thereafter.

\section{Retention rate in surgery}

The group that acquired medical license in 1993 was followed for the longest duration in this study (Fig. 3). The retention rates of both males and females showed a downward trend. The retention rate in females declined significantly to $48.4 \%$ in 2002 , stabilized thereafter, and then 


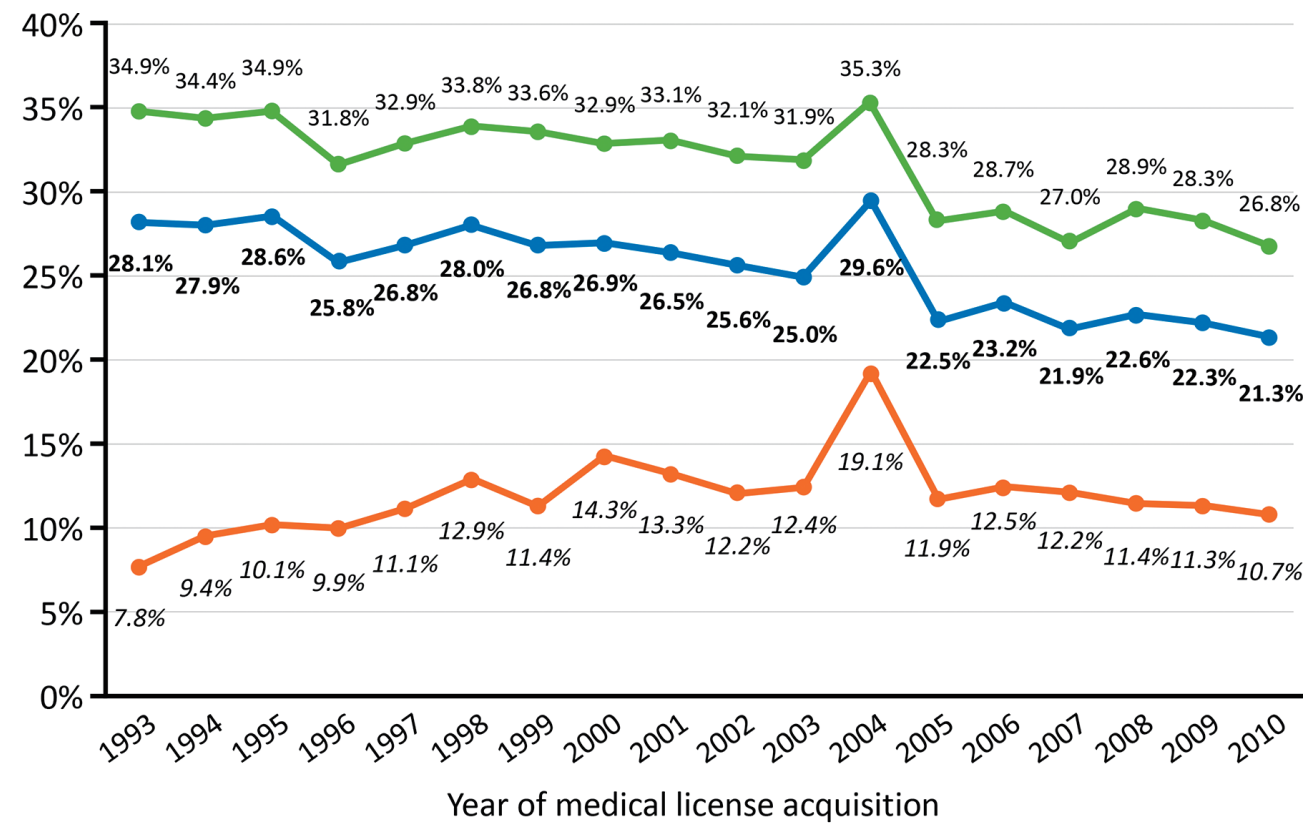

\section{Males and females combined - - Males $\quad-$ - Females}

Fig. 2. Proportions of doctors who selected surgery in early career, by year and by gender.

The proportion of male doctors choosing surgery was higher than that of female doctors throughout the study period. And, the decrease of surgeons started before the new training system, and decrease was accelerated after the system had started. While in females, the rate of selecting surgery tended to increase before the new training system, but declined slightly thereafter. Blue color shows males and females combined, green color indicates males only, and orange denotes females only.

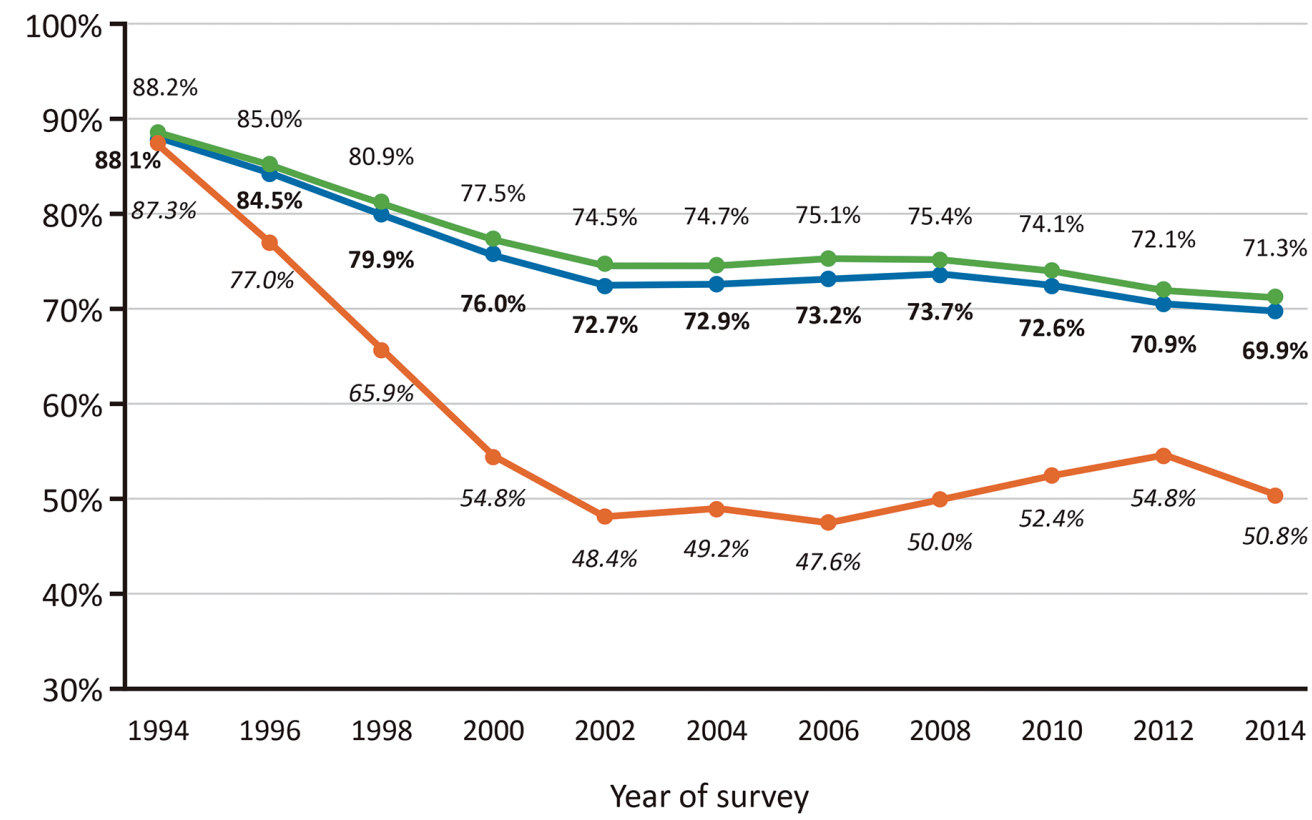

Males and females combined

Males

Females

Fig. 3. Retention rates of doctors who selected surgery in early career (medical license acquired in 1993).

The retention rate of both males and females who selected surgery at least once by the third survey after acquiring medical license in 1993 showed a downward trend. The retention rate in females declined significantly up to 2002, stabilized thereafter, and increased moderately from 2006 to 2012. Blue color shows males and females combined, green color indicates males only, and orange denotes females only. 
increased from $47.6 \%$ in 2006 to $50.8 \%$ in 2014 .

The retention rate after 10 years (2003) was almost stable $(72.4 \%)$ in males, but increased to $57.5 \%$ in females (Fig. 4). After more than 10 years, the gender difference of retention rate tended to decrease.

\section{Discussion}

Currently, the majority of surgeons are males, and the rate of selecting surgery as specialty among male doctors has been decreasing. In Japan, the selection rate of surgery as specialty already showed gradual decrease before the new clinical training system began in 2004, and the rate of the decrease was accelerated thereafter. This is a concern of the future. We also found that the retention rate in surgery was decreased, suggesting that surgery does not meet the conditions preferred by doctors of the younger generation. Without increasing both the selection rate and the retention rate, the number of surgeons in Japan will not increase.

Recently, Mizuno et al. (2014) showed high turnover rates in mid-career surgeons who are in the prime of their working life and in the position of directly supervising young doctors. These surgeons operate on many cases, work as mentor for young doctors, and play an important role as core surgeons of the department; as a result, they work long hours. Also, Mizuno et al. (2014) mentioned that among the 30 to 40 -year-old group of practicing doctors from 1996 to 2006, the number of general surgeons decreased by $22.6 \%$ while the total number of practicing doctors decreased by $0.7 \%$. By specialty, the rate of decrease from 1996 to 2006 was greater in general surgery $(-26.6 \%)$ than in obstetrics/gynecology $(-17.6 \%)$.

In Japan, it is pointed out that deterioration of the working environment in medicine has occurred. Many Japanese physicians in hospitals who work through a night shift continue to work in the following day shift without a rest interval, and surgeons are no exception. Doctors who are tired from working long hours may affect patient safety by missing ECG abnormalities (Friedman et al. 1971) and/ or reduced work efficiency (Dawson and Reid 1997; Taffinder et al. 1998). In the US, the surgical training was reported to be "malignant" (Yamauchi 2018). Nevertheless, after the Libby Zion case (Asch and Parker 1988), a case of death caused by medical errors due to overworked residents, 80 working hours per week was mandated. Before the new system, in one university hospital in 2002, surgical residents slept for an average of 4.4 hours, the shortest compared with residents in other departments of the hospital. Surgical residents worked on average 17.7 night sifts per month, the number of which was larger than any of other residents (Taoda et al. 2005). For patient safety and doctor's work-life balance, optimizing night shifts through

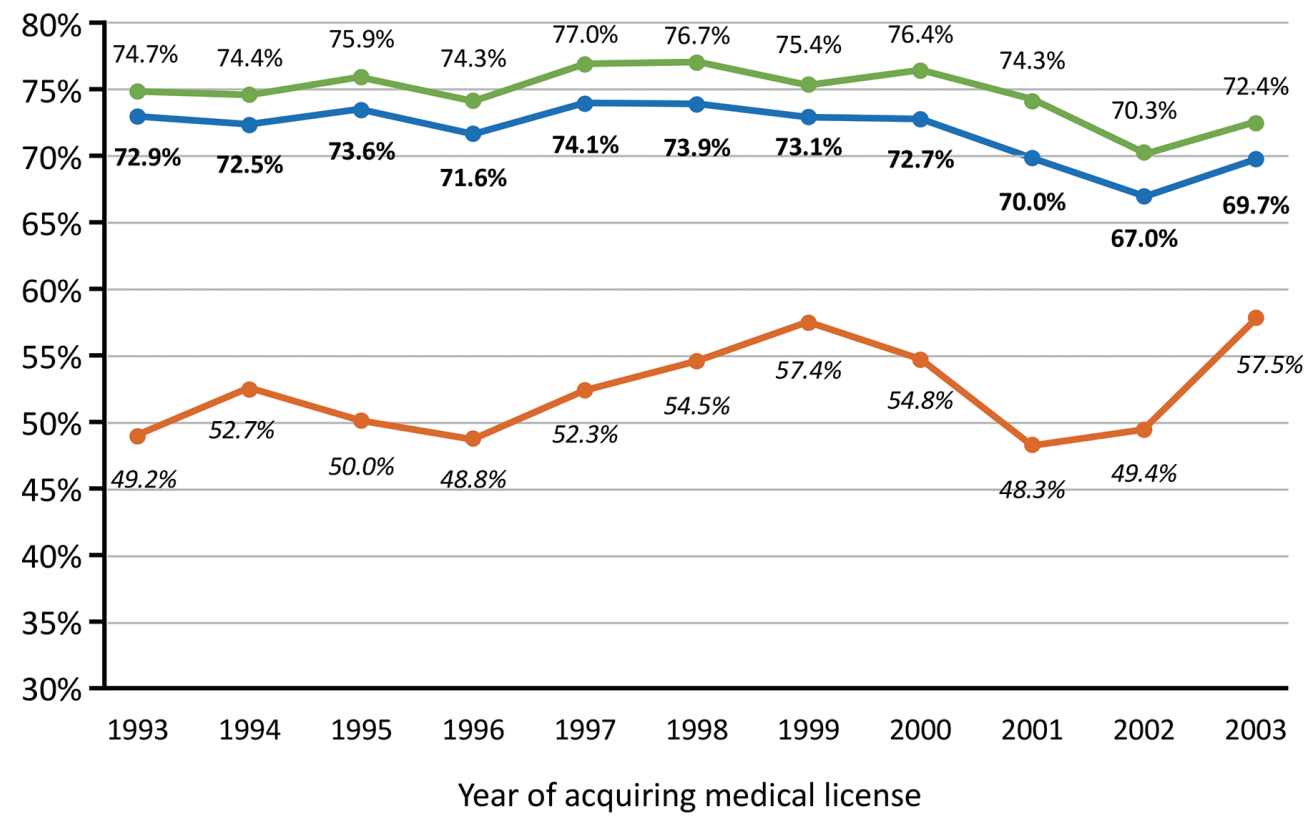

Males and females combined

Males

Females

Fig. 4. Retention rate in surgery after ten years of acquiring medical license.

The data show the retention rate in surgery at the sixth survey (11-12 years after acquiring medical license). The retention rate after 10 years was almost stable in males, but showed big changes with an upward trend in females, and the gender difference of retention rate tended to decrease. The Great East Japan Earthquake struck on March 11, 2011. And, the survey timing of license acquisition in 2001 and 2002, 10 years later was 2012. It is possible that the retention rate of doctors in surgery was affected by the earthquake. Blue color shows males and females combined, green color indicates males only, and orange denotes females only. 
hospital practice management approaches should be implemented, as notified by the Ministry of Health, Labor and Welfare (Notification: Optimization of holidays and night shifts at medical institutions, on March 19, 2002, Kihatsu No. 0319007). Currently, the epoch-making directives were notified to the public but they do not seem to be strict.

The Japanese labor standards law have not been applied to medical doctors from the past, because doctors govern themselves. Many violations of labor laws, such as Article 32 (working hours) and Article 37 (extra charges for overtime, holidays and late nights), have been found in national and public hospitals (Ehara 2011). Moreover, Article 36; Notification of agreement on overtime and holiday work, had been utilized for the convenience of the administrators of hospitals (Ehara 2011; Yoshikawa 2019). On the other hand, the Working Time Directive 2003 of the European Union stipulated to set a continuous 11-hour break every 24 hours (European Union 2003). It is time to consider changing the working style of Japanese doctors, and their work-life balance. According to the Notification from the Ministry of Education, Culture, Sports Science and Technology on June 28, 2019 (https://www.mext.go.jp/ a_menu/koutou/iryou/1418476.htm), a doctor is "a worker." By complying with the Labor Law, the working environment of doctors is expected to improve. When working continuously for long hours, scheduling resting interval is necessary.

Some suggestions have been proposed to protect surgeons from overwork and to prevent "karoshi (death from overwork)" (Bandou 2019; Yoshikawa 2019). First, separate the tasks that require a doctor's license and those that do not, and re-assign the latter to be done by non-doctoral workers such as nurses, technicians, and office workers. This is because non-doctoral workers who have a shift work system can more efficiently handle such tasks by workers working in different shifts, whereas doctors do not have a shift system and each needs to extend his/her working hours to incorporate such non-doctor-dependent tasks. On top of the demanding duties as doctors, these additional tasks make doctors even more overworked. Second, academic activities required for acquiring specialist accreditation are mandatory activities, and should not be classified as selfimprovement. Academic activities include attending clinical conferences in hospital, attending academic society annual meetings, writing case reports and scientific papers, and participating in research. Research and education to gain information and knowledge for patient care are essential for full-time physicians in academia (Okawa 2019). Third, hospital executive and managerial duties performed by doctors in charge of departments or hospitals require extra work and time. If doctors need to work overtime to complete these duties, they should be paid extra for working overtime, late night duties, and work during holidays (Ehara 2011).

The world has been changing and different generations have different thoughts and values (McNulty 2006). As a result, workplace conflict occurs. Currently, there is no clear definition of generation gap; professors and department heads belong to the generation of baby boomers $(-1964)$, mid-career surgeons in the so-called generation X (1965-80s), and young doctors in the yutori generation (1987- ) in Japan. We must understand the different ways of thinking about life and work in different generations. Young doctors in yutori generation often choose things comfortable to them, prefer flexible rules, and put priority on sense of fulfillment over pride. Older generations have to know young people's characters, and pay attention to acknowledge and praise, enhance motivation, and respond to request for recognition frequently seen in younger generation. To establish good working relationships with the younger generation, we have to know their style. For the perspective to a better future, it is indispensable to know the preference of colleagues of other generations, and learn to maintain work-life balance. Maiorova et al. (2007) reported that younger generations of general practitioners (GPs) prefer working conditions and practice settings different from those of older GPs, settings that provide more opportunity for leisure time, flexibility, and sharing of practice responsibilities. What is necessary for "work style reform for Japanese surgeons" is that those surgeons who do not want to change must change by themselves.

Work style reform includes improvement of human relationship in the workplace, and surgery in Japan lags behind the times in this aspect. Both academic and power harassments ranked high in a survey of surgeons on the stress at work and in private life during parenting (Tomizawa et al. 2020). In 2014, a search of judicial precedents regarding academic harassment in Japan found 30 cases (Kuwabara 2015). All cases were related to power structure at work in educational and research institutions. It has been pointed out that there is either no consultation office for harassment in institutions, or even if there is one, the office is not always functioning properly (Yukawa 2018). There are many cases that surgeons are harassed by their bosses during the residency rotation training, since bosses do not need to take harassment prevention courses in Japan.

The total number of female doctors working in medical facilities in Japan has continued to increase, and surveys conducted by the Japan Surgical Society (JSS) showed that the number of female members of JSS increased from 1,889 $(5 \%)$ in the first survey in 2008 (Tomizawa et al. 2009) to $3,247(8.2 \%)$ in the third survey in 2015 (Nomura et al. 2017). An article mentioned the trend of female surgeons leaving work in Japan (Tomizawa et al. 2016), while the data of this current study suggest for the first time that some females who left surgery returned to surgery later (Fig. 3). When the working environment allows, Japanese female surgeons could continue working after childbirth, and the retention rate will not have decreased that much. Some possible reasons for Japanese female surgeons leaving work are marriage [such as husband or partner with traditional 
Japanese idea does not want her to work (Japan Medical Association 2017)], child rearing (such as unavailability of daycare), and incompatibility with the work system (such as fulltime work and night duty). In addition to the existing supports, training and support for return to work, career development, and a comfortable working environment are needed. Also, efforts to reduce stress at work and in private life are also essential (Tomizawa et al. 2020). It is important to develop a plan to ensure that female doctors in surgery can build their career path by being able to acquire and renew specialist accreditation.

Both core male surgeons and male surgical specialists will decrease in number, and the number of female surgeons will increase in the near future. It has been estimated that by 2038 , the number of female surgeons with specialist accreditation will increase (2.48 times), while the number of male surgeons with specialist accreditation will decrease (0.85 times) (Aso et al. 2019). Therefore, surgical societies must focus on how to support career development for female surgeons. Furthermore, the proportion of young female doctors is increasing, and future health policies are needed to regulate the workforce of doctors (Kodama et al. 2012). The medical societies in Japan have to address the issue of gender equality in the election of executive officers (Tomizawa 2013). Studies in the past few years reported no female professor or associate professor in surgery at a national university (Okoshi et al. 2014) and no female member on the executive board of surgical societies (Tomizawa 2015). Improvement of this situation may be one of the important factors to stop the decline of female surgeons.

If female doctors in surgery are able to receive sufficient support from their family or work in facilities with good supporting system in place, which will solve their problems of sudden childcare crisis such as sick child and being a burden to their colleagues, it is possible that the slope of the retention rate of female doctors in surgery will become closer to that of male doctors in Fig. 3. Another issue is that there are two kinds of doctors in surgery: those who are being supported by others and those who are supporting others. Being supported doctors include those who are parenting, caring for aged parents, and working with illness. Supporting doctors are male and female doctors working with those needing support. If doctors who are supporting other doctors work comfortably and able to care for their family well, the retention rate of surgeons in general will stabilize or even increase, and the gap between retention rates of male and female surgeons will gradually improve.

There are some limitations in this study. First, the status of acquisition and renewal of specialist accreditation by gender, age or number was not examined in this study. Second, the tendency in surgery was examined alone in this study, and did not compare with other departments. Third, because "resident" was not included as a choice under clinical department in the survey form of 2004, residents who were being trained at the department of surgery by rotation at the timing of survey might have selected "surgery" as their specialty. This may have caused the spikes seen in male, female, and total doctors in the 2004 survey (Fig. 2).

In conclusion, surgery was getting harder than we had expected; surgery is already an "endangered species." It is therefore necessary to make the surgery specialty attractive to young doctors to increase the selection rate. It is also important to support a good work-life balance to improve the retention rate, since doctors of the younger generation tend to value their private life. Additionally, for female surgeons, career development and support for return to work are essential.

\section{Acknowledgments}

The author thanks Dr. Teresa Nakatani for her useful discussions.

This study was supported by a Grant-in Aid for Scientific Research (C) No. 16K08884 from the Japan Society for the Promotion of Science.

\section{Conflict of Interest}

The authors declare no conflict of interest.

\section{References}

Asch, D.A. \& Parker, R.M. (1988) The Libby Zion case. One step forward or two steps backward? N. Engl. J. Med., 318, 771-775.

Aso, S., Yasunaga, H. \& Koike, S. (2019) Estimation of the number of medical specialists in the future using the National Survey on Doctors/Dentists/Pharmacists. J. Health Welf. Stat., 66, 31-36 (in Japanese).

Bandou, S. (2019) The present state of the death from overwork and the suicide of doctors in Japan. Jpn. J. Acute Med., 43, 1122-1127 (in Japanese).

Dawson, D. \& Reid, K. (1997) Fatigue, alcohol and performance impairment. Nature, 388, 235.

Ehara, A. (2011) Labor-related laws and physicians. J. Jpn. Soc. Clin. Anesth., 31, 1029-1035 (in Japanese).

European Union (2003) Directive 2003/88/EC of the European Parliament and of the Council of 4 November 2003 concerning certain aspects of the organisation of working time.

https://eur-lex.europa.eu/eli/dir/2003/88/oj [Accessed: May 19, 2020].

Friedman, R.C., Bigger, J.T. \& Kornfeld, D.S. (1971) The intern and sleep loss. N. Engl. J. Med., 285, 201-203.

Iinuma, M., Tahara, K., Takaku, F., Ogawa, A. \& Fukui, T. (2010) Compulsory postgraduate clinical training system: its impact, amendment and perspective. J. Jpn. Med. Assoc., 138, 19932005 (in Japanese).

Japan Medical Association (2017) Survey report on the current working conditions of female doctors.

[Updated August, 2017].

https://www.med.or.jp/joseiishi/wp-content/uploads/2018/10/ h29wd_survey.pdf

[Accessed: May 19, 2020] (in Japanese).

Kitamura, K. (2015) Ten years after implementation of the mandatory residency in Japan. Nihon Naika Gakkai Zasshi, 104, 2533-2538 (in Japanese).

Kodama, T., Koike, S., Matsumoto, S., Ide, H., Yasunaga, H. \& Imamura, T. (2012) The working status of Japanese female physicians by area of practice: cohort analysis of taking leave, 
returning to work, and changing specialties from 1984 to 2004. Health Policy, 105, 214-220.

Kuwabara, H. (2015) Court cases concerning academic harassment and countermeasures: from a lawyer's perspective. Health Care, 57, 308-314 (in Japanese).

Maiorova, T., Stevens, F., van der Velden, L., Scherpbier, A. \& van der Zee, J. (2007) Gender shift in realisation of preferred type of GP practice: longitudinal survey over the last 25 years. BMC Health Serv. Res., 7, 111.

McNulty, E.J. (2006) Can you manage different generations? Harvard Business School "Working Knowledge" newsletter, 17 April 2006.

Mizuno, Y., Narimatsu, H., Kodama, Y., Matsumura, T. \& Kami, M. (2014) Mid-career changes in the occupation or specialty among general surgeons, from youth to middle age, have accelerated the shortage of general surgeons in Japan. Surg. Today, 44, 601-606.

Nomura, S., Tomizawa, Y., Ohtsu, H., Ogawa, T., Shibazaki, I., Shimada, M., Takeshita, E., Hanasaki, K., Hanashi, T., Yamashita, H., Akashi, S., Yamauchi, H., Iwase, H., Maeda, K. \& Nakamura, S. (2017) Current status of support for female doctors in the specialist medical societies of the Japanese association of medical science in 2015: results of a questionnaire survey. J. Jpn. Surg. Soc., 118, 668-672 (in Japanese).

Okawa, A. (2019) Working hours reform in a university hospital. Jpn. J. Acute Med., 43, 1184-1188 (in Japanese).

Okoshi, K., Nomura, K., Fukami, K., Tomizawa, Y., Kobayashi, K., Kinoshita, K. \& Sakai, Y. (2014) Gender inequality in career advancement for females in Japanese academic surgery. Tohoku J. Exp. Med., 234, 221-227.

Taffinder, N.J., McManus, I.C., Gul, Y., Russell, R.C. \& Darzi, A. (1998) Effect of sleep deprivation on surgeons' dexterity on laparoscopy simulator. Lancet, 352, 1191.

Taoda, K., Nakamura, K., Kitahara, T. \& Nishiyama, K. (2005) Sleep situation of residents at a national university hospital. $J$. Occup. Health, 47, 246-253 (in Japanese).
Tomizawa, Y. (2015) Gender gap in medicine: only one woman councilor in the Japan Surgical Society. Tohoku J. Exp. Med., 235, 97-102.

Tomizawa, Y. (2013) Women in surgery: little change in gender equality in Japanese medical societies over the past 3 years. Surg. Today, 43, 1202-1205.

Tomizawa, Y., Hagihara, M., Nomura, S., Akashi-Tanaka, S., Shibazaki, I., Hanashi, T., Yamauchi, H. \& Nakamura, S. (2020) Stress at work and in private life during parenting: a survey of members of the Japan surgical Society. J. Tokyo Wom. Med. Univ., 90, 30-37 (in Japanese).

Tomizawa, Y., Kawase, K., Yorozuya, K., Nagata, Y. \& Teramoto, T. (2009) Current status of support for female doctors in the specialist medical societies of the Japanese Association of Medical Sciences: results of a questionnaire survey. Nihon Geka Gakkai Zasshi, 110, 154-161.

Tomizawa, Y., Miyazaki, S., Nishida, H. \& Uetsuka, Y. (2016) Trend of medical doctors leaving current employment in Japan: analysis of data of employment status survey conducted by ministry of internal affairs and communications. J. Tokyo Wom. Med. Univ., 86, 215-222.

Yamauchi, H. (2018) Everyone's working styles reform for the ideal of gender equality: reconsider now to pursue task shifting and task sharing. J. Jpn. Surg. Soc., 119, 253-255 (in Japanese).

Yamazaki, Y., Horiguchi, I. \& Marui, E. (2010) Comparison of turnover issues among female physicians by generation. Med. Educ., 41, 411-416 (in Japanese).

Yoshikawa, T. (2019) Karoshi in doctors: to improve the working environment of doctors. J. Jpn. Med. Assoc., 148, 1301-1304 (in Japanese).

Yukawa, Y. (2018) Academic harassment in research and educational institutions: create an educational setting conducive to learning and working. Jpn. J. Nurs. Educ., 59, 193-197 (in Japanese). 